\title{
On Innovation, Appropriateness, Intervention Design...
}

Shortly after attending the ICSID-IDSA CONNECTING '07 World Design Congress in San Francisco, EICs Jon and Richard sat down to discuss the conference and its relationship to this issue of interactions.

Jon: I'm concerned with the overabundance of the word "innovation" in our professional discipline. At CONNECTING '07, the theme was neither subtle nor convincing: Nearly every speaker talked about innovation (some better than others), yet no one over the course of four days managed to define the term. Apparently, if a business isn't focused entirely on innovation right now, their business is completely ruined and they won't be around in a hundred years.

I've recently done a mental inventory of the products, software, and services that I use and that I cherish. The items I hold dear to my heart are either one-offs (craft oriented and thus not in the realm of the innovation discussion) or refined and subtle (they are appropriate more than they are innovative). As we see a trend in society toward "slow" design (clearly juxtaposed with fast-food culture), the bloat of features and functionality that seem to go hand in hand with being new and different are dramatically misplaced.

On top of this, the majority of the companies that are clamoring for increased innovation haven't proven that they can solve the older problem of quality: I don't need more "new" and "innovative" features in Windows; I just need the bloody thing to work without crashing.

You do a lot of coaching and teaching companies to be more innovative. Why don't you get them to be more appropriate, or refined, or polished, instead?

Richard: Actually, my coaching and teaching focus on moving user experience into a position of greater corporate attention and influence-on helping to enable companies to do the kinds of things Secil

(continued on page 79)

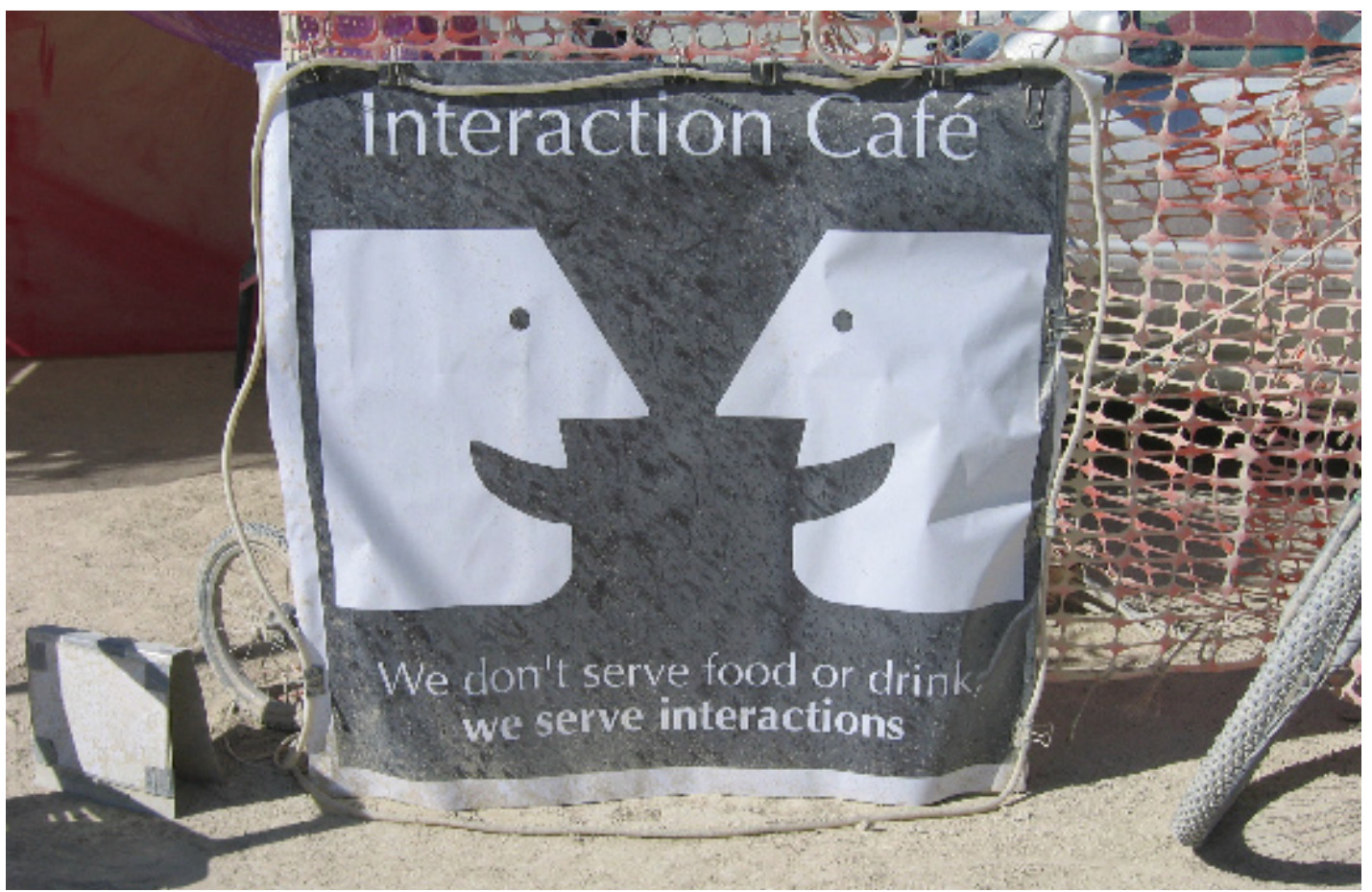




\section{INTERACTIONS CAFE}

(continued from page 80)

Watson describes in her article in this issue. Roger Martin referred to this as intervention design in his conference plenary on "Design Thinking: The Next Competitive Advantage," and I'm sure we'll offer more articles on this in future issues.

Sometimes such interventions mean helping companies organize and do things in such a way that more appropriate, refined, or polished user experiences will result. But they do sometimes mean helping companies do things so that they can be more innovative. However, innovation can be an important part of making user experiences more appropriate, refined, or polished. I think Hugh Dubberly's cover story on the model of innovation captures that.

Hugh's model also addresses the insight required of all of this, stating that "immersion within the context is almost always essential" to achieve such insight. I often coach and advise companies on how to achieve such immersion effectively, and the article by Stefana Broadbent and Valerie Bauwens contributes guidance as well. That article also reveals ethnographic research findings that advise against certain types of innovation since they are likely to yield user experiences that are inappropriate.

Clearly, ethnographic research was a big topic at CONNECTING '07. What struck me was the extent to which members of this particular design community seem to embrace such research while they struggle with the role it should play in their work.

Jon: Hugh's model captures the idea of refinement and polish in execution-his process exemplifies the sort of rigor that is necessary to call something "appropriate." Secil spent nearly five years working on the advancements she's detailed, and Stefana's work has spanned nearly as long. Innovation is nearly always accompanied by a push for speed. Innovate faster! Innovate now! But all of the truly timeless "innovations" were born of a long, drawn-out, and extremely rigorous process.

I found it interesting that, also at CONNECTING '07, many of the speakers, including IDEO's President and CEO Tim Brown, cited Charles and Ray Eames as being influential in their view of the creation of iconic design solutions. Charles and Ray Eames spent their career refining a process of design that emphasized craft, patience, care, and detail, and Charles is referenced as saying "innovate as a last resort." Their view of design, engineering, production, and development was one focused on the cultural sensitivity both Gabe White and Gary Marsden introduced: appropriateness, not the push for newer, and faster, and bigger.

Richard: Well, today's Internet is an example of a truly timeless innovation born of a long, drawn-out process. But as described in Glenn Kowack's early history of the Internet, that process was not exactly rigorous.

However, new ideas that have value-that can, for example, lead to greater appropriateness—can be generated faster via processes that have rigor. Ethnographic research methods can be a key component of such processes, as can the involvement of multiple disciplines in ways akin to those Secil describes.

Sir Ken Robinson's amazing plenary at the conference spoke to this. Ken defined creativity as "the process of generating original ideas that have value," a process that "more often than not comes about through the interaction of different disciplinary ways of seeing things." However, according to Ken, our creativity has been systematically educated out of us.

Certain process interventions that attempt to resurrect that creativity can happen and be effective rather quickly, but long-lasting interventions-e.g. the cultural interventions being orchestrated by Secil and Stefana-can take a lot of time. As Roger Martin described, the ways of thinking that are dominant in business create an environment that is hostile to such change. But those companies that can achieve such change are likely to also achieve competitive advantage.

Jon: Maybe that's one of the key distinctions between design and innovation: I see design as something that is inherently separate from business. It can be twisted and manipulated into a business context, often with great financial rewards for those who understand how to position it correctly. But on its own, design is about shaping culture and society, and the construct of profit and competitive advantage is arbitrary (although certainly appealing for many). The struggle we see, as academics try to understand "design research," and the emphasis that has been placed recently on developing nations and on issues like sustainability (an issue addressed extensively during the conference and by Eli Blevis in this magazine), indicate a return toward what could be thought of as a more liberal view of design: appropriate, culturally resonant, and profitable only incidentally. Personally, I think this shift is sorely needed and long overdue; in a culture overcome with consumption and stuck with an abstract view of happiness as lots of money, perhaps design can be the answer not only to our environmental woes, but to our spiritual woes, too. - $\quad$ Richard Anderson \& Jon Kolko
Permission to make digital or hard copies of all or part of this work for personal or classroom use is granted Without the fee, provided
that copies are not made or distributed for profit or commercial advantage, and that copies bear this notice and the full citation on the first page. To copy otherwise, to republish,
to post on services or to redistribute to lists, requires prior specific permission and/or a fee. $\odot \mathrm{ACM}$ 1072-5220/08/0100 $\$ 5.00$ 